\title{
Two Transcription Factors Can Direct Three Photoreceptor Outcomes from Rod Precursor Cells in Mouse Retinal Development
}

\author{
Lily Ng, ${ }^{1}$ Ailing Lu, ${ }^{1}$ Alok Swaroop, ${ }^{1}$ David S. Sharlin, ${ }^{1}$ Anand Swaroop, ${ }^{2}$ and Douglas Forrest ${ }^{1}$ \\ ${ }^{1}$ NIDDK, Clinical Endocrinology Branch, and ${ }^{2} \mathrm{NEI}$, Neurobiology, Neurodegeneration and Repair Laboratory, National Institutes of Health, Bethesda, \\ Maryland 20892-1772
}

The typical mammalian visual system is based upon three photoreceptor types: rods for dim light vision and two types of cones (M and S) for color vision in daylight. However, the process that generates photoreceptor diversity and the cell type in which diversity arises remain unclear. Mice deleted for thyroid hormone receptor $\beta 2$ (TR $\beta 2$ ) and neural retina leucine zipper factor (NRL) lack M cones and rods, respectively, but gain $S$ cones. We therefore tested the hypothesis that NRL and TR $\beta 2$ direct a common precursor to a rod, $M$ cone, or $S$ cone outcome using $\mathrm{Nrl}^{b 2 / b 2}$ "knock-in" mice that express TR $\beta 2$ instead of NRL from the endogenous Nrl gene. $\mathrm{Nrl}$ "b2/b2 mice lacked rods and produced excess $\mathrm{M}$ cones in contrast to the excess $\mathrm{S}$ cones in $\mathrm{Nrl}^{-1-}$ mice. Notably, the presence of both factors yielded rods in $\mathrm{Nrl}^{+/ b 2}$ mice. The results demonstrate innate plasticity in postmitotic rod precursors that allows these cells to form three functional photoreceptor types in response to NRL or TR $\beta 2$. We also detected precursor cells in normal embryonic retina that transiently coexpressed $\mathrm{Nrl}$ and TR $\beta 2$, suggesting that some precursors may originate in a plastic state. The plasticity of the precursors revealed in $\mathrm{Nrl}^{b 2 / 62}$ mice suggests that a two-step transcriptional switch can direct three photoreceptor fates: first, rod versus cone identity dictated by NRL, and second, if NRL fails to act, $M$ versus $S$ cone identity dictated by TR $\beta 2$.

\section{Introduction}

The visual capability of a species depends upon the generation of distinct photoreceptor types. Most mammals, including mice, possess three photoreceptor types: rods for dim light vision and two cone types for bright light vision. Cone types are defined by expression of medium-long (M) and short (S) wavelengthsensitive opsin photopigments, respectively, that allow color discrimination (Nathans, 1999). In the retina, multipotent, proliferative progenitor cells produce postmitotic progeny, or precursors, with diverse neuronal fates (Carter-Dawson and LaVail, 1979b; Cepko et al., 1996; Adler and Raymond, 2008). Progenitors are thought to change their properties as development progresses, thereby permitting the generation of the requisite variety of neuronal types, including rods, cones, horizontal, amacrine, bipolar, and ganglion cells that constitute the mature retina (Livesey and Cepko, 2001; Brzezinski and Reh, 2010). Classical cell birth-dating studies using ${ }^{3} \mathrm{H}$-thymidine pulses in early mouse development followed by morphological identification of

Received April 5, 2011; revised May 27, 2011; accepted June 10, 2011.

Author contributions: L.N. and D.F. designed research; L.N., A.L., Alok Swaroop, and D.S.S. performed research; Anand Swaroop contributed unpublished reagents/analytic tools; L.N., A.L., Alok Swaroop, D.S.S., Anand Swaroop, and D.F. analyzed data; L.N. and D.F. wrote the paper.

This work was supported by the NIH intramural research program at NIDDK and NEI. We thank M. Ma and J. Nellissery for assistance, W. Wood and E. C. Ridgway for plasmids, T. F. Davies for Tshr ${ }^{-1-}$ mice, and E. N. Pugh Jr and R. Bush for advice on ERG analyses.

The authors declare no competing financial interests.

Correspondence should be addressed to Douglas Forrest, at the above address. E-mail: forrestd@niddk.nih.gov. DOI:10.1523/JNEUROSCI.1709-11.2011

Copyright $\odot 2011$ the authors $\quad 0270-6474 / 11 / 3111118-08 \$ 15.00 / 0$ cell types at adult ages indicated that cones are generated in the embryo, whereas rods are produced over a longer time extending into the postnatal period (Carter-Dawson and LaVail, 1979b; Young, 1985). However, rods and cones remain morphologically indistinct for much of their early life history, which has hindered direct studies of the events that generate photoreceptor diversity.

Transcription factors play critical roles throughout the course of photoreceptor differentiation from multipotent progenitor cell to postmitotic precursor to terminally differentiated neuron. Regarding the mechanisms by which photoreceptor diversity arises, we previously reported that neural retina leucine zipper factor (NRL, encoded by $\mathrm{Nrl}$ ) and thyroid hormone receptor 2 (TR $\beta 2$, one of the receptor isoforms encoded by Thrb), profoundly influence photoreceptor fates. $\mathrm{Nrl}^{-1-}$ mice lack rods but gain excess $S$ cones (Mears et al., 2001), whereas Thrb2 ${ }^{-1-}$ mice lack $\mathrm{M}$ cones, and all cones instead express $\mathrm{S}$ opsin $(\mathrm{Ng}$ et al., 2001). Moreover, bromodeoxyuridine labeling indicates that NRL and TR $\beta 2$ are expressed in postmitotic precursors rather than dividing progenitors (Akimoto et al., 2006; Jones et al., 2007), leading us to hypothesize that in mice, photoreceptor diversity originates in a common, postmitotic photoreceptor precursor with default $\mathrm{S}$ cone properties.

To investigate the nature of the cell type in which photoreceptor diversity arises, we analyzed mice in which $\mathrm{Nrl}$ was replaced with a Thrb mini-gene that expresses TR $\beta 2$. The data demonstrate that postmitotic precursors that would normally form rods can alternatively produce $\mathrm{M}$ cones, $\mathrm{S}$ cones, or rods, depending upon the relative activities of NRL and TR $\beta 2$. We propose that the innate plasticity of this precursor allows a sequential, two- 
step transcriptional switch to direct three photoreceptor cell fates.

\section{Materials and Methods}

Mouse strains. $\mathrm{Nrl}^{-1-}$ mice were on a C57BL/6J background (Mears et al., 2001) and $T s h r^{-1-}$ mice on a $129 / \mathrm{Sv} \times \mathrm{C} 57 \mathrm{BL} / 6 \mathrm{~J}$ background (Marians et al., 2002). Thrb $b^{\text {tm2/tm2 }}\left(\mathrm{Thrb2}^{-/-}\right)$mice (Ng et al., 2001) on a $129 / \mathrm{Sv} \times \mathrm{C} 57 \mathrm{BL} / 6 \mathrm{~J} \times \mathrm{DBA}$ background carried a targeted replacement of lac $Z$ in the TR $\beta 2$-specific exon of Thrb, resulting in expression of $\beta$-galactosidase from the endogenous TR $\beta 2$ promoter. The $N r l p$-GFP transgene (Akimoto et al., 2006) was on a wild-type C57BL/6 background; these mice also carried a Thrb2p-lacZ transgene with the natural $\mathrm{TR} \beta 2$ promoter and intron enhancer that direct expression in immature cones (Jones et al., 2007) to allow triple fluorescent analyses. $\mathrm{Nr} l^{b 2 / b 2}$ mice on a C57BL/ 6 background were derived by targeted mutagenesis in C57BL/6 ES cells by Ozgene Pty Ltd. The targeting vector carried 5' and $3^{\prime}$ homology arms of 4.7 and $4.3 \mathrm{~kb}$, respectively, of $\mathrm{Nrl}$ genomic DNA flanking a mouse TR $\beta 2$ cDNA (gift from W. Wood and E. C. Ridgway, University of Colorado, Denver, Colorado) (Wood et al., 1991) with a 59 bp $5^{\prime}$ non-coding sequence before the TR $\beta 2$ ATG codon, a 126 bp 3' untranslated sequence after the stop codon, an SV40 polyadenylation site, and a neomycin ( $\mathrm{Neo}$ )-resistance gene flanked by loxP sites. Chimeric mice derived from a recombinant ES cell clone were crossed with $\mathrm{Cre}$-transgenic mice to remove $\mathrm{Neo}$; the Cre transgene was removed by out-crossing. Targeting was ascertained by Southern blot analysis. $\mathrm{Nrl}^{+/ \mathrm{b} 2}$ mice were crossed to produce $+/+,+/ \mathrm{b} 2$, and $\mathrm{b} 2 / \mathrm{b} 2$ progeny for analyses. Genotypes were determined using a three-primer PCR with primers: $\mathrm{Nrl}$-104F, 5'-GAACACCTCTCTCTGCTCAGTCCC; Thrb21522R, 5'-GGCTGAGGGCCATGTCCAAGTC; $N r l$-512R, 5'CTGGACATGCTGGGCTCCTGTCTC, giving bands of 450 and $250 \mathrm{bp}$ for wild-type and $\mathrm{Nrl}$-b2 alleles, respectively. For developmental studies before adult ages, mice of either sex were analyzed. For histology and electroretinogram studies at adult ages, the sex of mice analyzed is given. Studies were performed according to approved protocols at NIDDK/NIH.

In situ hybridization and quantitative PCR analysis. In situ hybridization was performed with riboprobes as described previously (Jia et al., 2009). For 8 -week-old mice (see Fig. 4A), groups of 3 mice of either sex for each genotype were analyzed. The Thrb probe spanned the common C terminus of TR $\beta 2$ and TR $\beta 1$ (accession no. NM_001113417, coordinates 124-1701). For real-time quantitative PCR, retinal RNA was pooled from 3-5 mice. Gene expression levels were normalized to actin (Jia et al., 2009). Primers, accession numbers, and amplicon sizes are as follows: Opn1mw NM_008106, 162 bp, forward (F), 5'TCGAAACTGCATCTTACATCTC, reverse (R), 5'GGAGGTAAAACATGGCCAAA; Opn1sw AF190670, 176 bp, F, 5'TGCTGGGGATCTGAGATGAT, R, 5'AATGAGGTGAGGCCATTCTG, Thrb2 NM_009380.3, 208 bp, F, 5'CCTGTAGTTACCCTGGAAACCTG， R，5'TACCCTGTGGCTTTGTCCC; Actb NM_007393.3, 222 bp, F, 5'TGCTGTCCCTGTATGCCTCTG, R, 5'TTGATGTCACGCACGATTTCC. Most primers were designed using PrimerBank guidelines (http://pga.mgh.harvard.edu/ primerbank).

Western blot analysis. Retinas from 2-4 embryos or mice were pooled to prepare whole-cell protein extracts as described previously (Lu et al., 2009). For adults, $15 \mu \mathrm{g}$ samples and for embryos or neonates, $25 \mu \mathrm{g}$ samples (unboiled) were analyzed by PAGE; rhodopsin was analyzed in 3 $\mu \mathrm{g}$ samples. Antibodies, dilutions, and sources are as follows: Nrl, rabbit polyclonal, 1:10,000 (Swain et al., 2001); TR $\beta 2$, rabbit polyclonal, 1:2500 (Ng et al., 2009); M opsin, rabbit polyclonal, 1:1000 (Millipore Bioscience Research Reagents Ab5405); S opsin, goat polyclonal, 1:250 (Santa Cruz Biotechnology sc14363); rhodopsin, mouse monoclonal, 1:2000 (Millipore Bioscience Research Reagents MAb5316); actin, mouse monoclonal, 1:5000 (Millipore Bioscience Research Reagents MAb1501).

Immunohistochemistry. Ten-micrometer cryosections were incubated with antibodies and analyzed using a Leica SPE or Zeiss LSM510 confocal microscope and a $63 \times$ oil-immersion lens (NA 1.4). Counts of TR $\beta 2+$ and GFP + cells were determined in a single, $1 \mu \mathrm{m} z$-plane in mid-retinal sections. Counts were determined in 3 fields in the outer neuroblastic layer in the superior, middle, and inferior regions each of retina for groups of 3-5 mice. Antibody types, dilutions for use, and sources are as
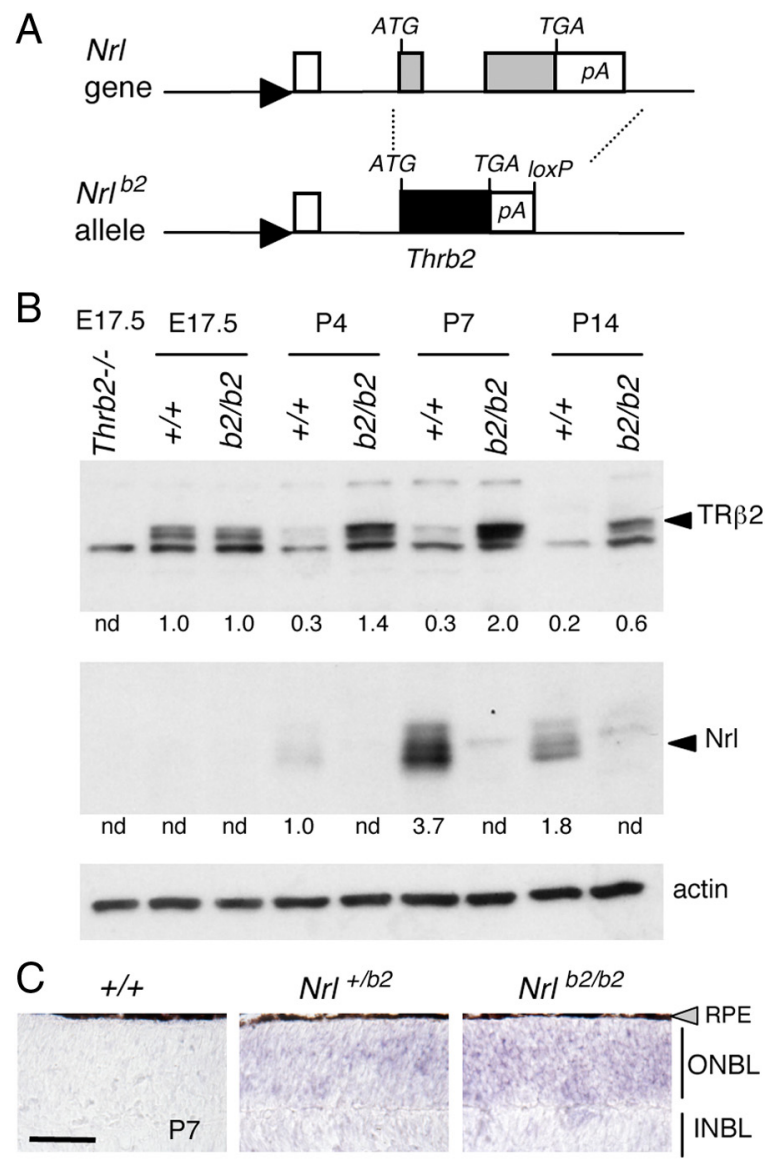

Figure 1. Targeted replacement of Nrl gene with a Thrb2 gene. A, A Thrb2 CDNA, inserted at the start codon of $\mathrm{Nrl}$, replaced both $\mathrm{Nrl}$ coding exons (gray boxes), creating the $\mathrm{Nr}^{\mathrm{b} 2}$ allele. Filled triangle, Nrl gene promoter, open box, $5^{\prime}$-non-coding exon; TGA, stop codon; pA, polyadenylation site; loxP, residual loxP site after deletion of Neo selection gene. $\boldsymbol{B}$, Western blot analysis showing expression of TR $\beta 2$ in Nr/b2/b2 mice. Arrowheads, specific bands for TR $\beta 2$ $(\sim 58 \mathrm{kDa})$ and NRL ( $29-35 \mathrm{kDa})$. Thrb2 ${ }^{-1-}$ lane, TR $\beta 2$-deficient control at embryonic day 17.5 (E17.5). Numbers below lanes are signals quantified by densitometry relative to an arbitrary value of 1.0 in $+1+$ mice at the earliest age of detection; nd, not detectable. $C$, In situ hybridization showing ectopic expression of TR $\beta$ mRNA over the outer neuroblastic layer (ONBL) in $\mathrm{Nrl}^{+/ 62}$ and $\mathrm{Nrl}^{\mathrm{b} / / 62}$ mice at P7. Endogenous TR $\beta 2$ mRNA drops to low levels in the small cone population in $+/+$ neonates. Scale bar, $50 \mu \mathrm{m}$. INBL, Inner neuroblastic layer. RPE, Retinal pigmented epithelium (gray triangle).

follows: S opsin, rabbit polyclonal, 1:1000 (Millipore Bioscience Research Reagents AB5407); $\beta$-galactosidase (E. coli), mouse monoclonal, 1:200 (Promega Z378A); TR $\beta 2$, rabbit polyclonal, 1: 2500 (Ng et al., 2009). The polyclonal antiserum raised in rabbit against full-length mouse NRL, described previously (Swain et al., 2001), was purified to select for the IgG fraction using protein A-Sepharose beads. This IgG fraction was used at 1:1000 dilution for immunohistochemistry.

Histology. Three-micrometer glycol methacrylate sections were stained with hematoxylin and eosin (Jia et al., 2009). Cone and rod nuclei were counted in $165-\mu \mathrm{m}$-long fields of the outer nuclear layer (ONL) in 2 representative fields per section on 3 mid-retinal, vertical sections in groups of 3 mice (all males). Statistical tests used Student's $t$ test.

Electroretinogram analysis. The electroretinogram (ERG) was recorded using an Espion Electrophysiology System (Diagnosys LLC) on 8- to 10 -week-old mice anesthetized with (in milligrams per gram body weight) 25 ketamine, 10 xylazine, and 1000 urethane, as described previously (Lyubarsky et al., 1999; Ng et al., 2010). Briefly, photopic cone b-wave responses were measured with rod responses suppressed by constant green light $(\lambda 520 \mathrm{~nm})$ at $10 \mathrm{~cd} / \mathrm{m}^{2}$.S opsin responses were evoked with a UV light-emitting diode (LED) with a peak at $367 \mathrm{~nm}$ and intensities of $0.0001,0.0002,0.00032,0.00056,0.001,0.0018,0.0032,0.0056$, 
$0.01,0.0178,0.0316$, and $0.056 \mathrm{~cd} / \mathrm{m}^{2}$. M opsin responses were evoked using an LED with a peak at $520 \mathrm{~nm}$ and intensities of $0.5,1,1.26$, $1.58,2,2.51,3.16,3.98,5.01,6.31,7.94,10$, $12.59,15.84,19.95,25.12,32$, and $38 \mathrm{~cd} / \mathrm{m}^{2}$. Scotopic rod responses were evoked after overnight dark adaptation using an LED with a peak at $520 \mathrm{~nm}$ at intensities of $1 \times 10^{-6}, \times$ $10^{-5}, \times 10^{-4}, \times 10^{-3}$, and $\times 10^{-2} \mathrm{~cd} / \mathrm{m}^{2}$. The ERG was recorded twice on separate groups of 4-6 mice (7-8 weeks old) of either sex, with males and females in approximately equal proportions for each of the six genotypes analyzed.

\section{Results}

Ectopic expression of TR $\beta 2$ from the $\mathrm{Nrl}$ gene

Our hypothesis that three photoreceptor types originate from a common, postmitotic precursor with default $S$ cone properties was suggested by the profound shifts in photoreceptor fates observed in $\mathrm{Nrl}^{-1-}$ and Thrb2 $2^{-I-}$ mice, both of which gain $\mathrm{S}$ cones at the expense of rods and $\mathrm{M}$ cones, respectively (Swaroop et al., 2010). To define the roles of NRL and TR $\beta 2$ in a common precursor, we investigated photoreceptor fates and function in mice in which the $\mathrm{Nrl}$ gene was replaced with a TR $\beta 2$-expressing cassette (Thrb2) by homologous recombination (Fig. 1A). This model would allow us to determine: (1) in heterozygotes, the consequence of coexpression of NRL and $\mathrm{TR} \beta 2$ in a defined precursor population that normally forms rods; and (2) in homozygotes, the role of TR $\beta 2$ in the absence of NRL in this same precursor population.

Western blot analysis revealed the predicted loss of NRL and ectopic expression of TR $\beta 2$ in the retina of mice homozygous for this $N r l^{b 2}$ allele (Fig. 1B). Normally, $N r l$ expression peaks during the first postnatal week, whereas TR $\beta 2$ peaks in utero (Akimoto et al., 2006; Ng et al., 2009), correlating with the peaks of birth of immature rods and cones, respectively (Carter-Dawson and LaVail, 1979b). In $\mathrm{Nr}^{b 2 / b 2}$ mice, TR $\beta 2$ showed protracted postnatal expression with a peak at postnatal day 7 (P7), as expected when expressed from the endogenous $\mathrm{Nrl}$ promoter. In situ hybridization analysis revealed ectopic expression of TR $\beta 2$ mRNA over the entire outer neuroblastic layer (ONBL) of the retina in $\mathrm{Nr} l^{b 2 / b 2}$ and $\mathrm{Nrl}^{+/ b 2}$ mice at $\mathrm{P} 7$, consistent with expression in the large precursor population that normally forms rods (Fig. 1C). In contrast, TR $\beta 2$ mRNA expression in the small cone population in wild-type $(+/+)$ mice had declined to nearly undetectable levels at P7.

\section{Histology of the photoreceptor layer in $\mathrm{Nrl}^{+/ b 2}$ and $\mathrm{Nrl}^{\mathrm{b2/b2}}$ mice}

The retina of adult $\mathrm{Nr}^{b 2 / b 2}$ mice was morphologically indistinguishable from that of $\mathrm{Nrl}^{-1-}$ mice in displaying excess cones and a complete absence of rods, as expected following loss of $\mathrm{Nrl}$ (Fig. 2A,B). $\mathrm{Nrl}^{b 2 / b 2}$ mice, like $\mathrm{Nrl}^{-/-}$mice (Daniele et al., 2005), also displayed shortened outer segments and "rosette" distortions of the ONL, possibly due to aberrant packing and displacement of cone cell bodies, which are larger than rod cell bodies. In contrast, in heterozygous $\mathrm{Nrl}^{+/ b 2}$ mice, normal numbers of cones and rods were present (Fig. 2A,C). Cones were identified by their large nuclei with dispersed chromatin and their location near the outer edge of the ONL, whereas rods were distinguished by their small, densely stained nuclei and their large numbers distributed throughout the ONL (Carter-Dawson and LaVail, 1979a). Thus, ectopic expression of TR $\beta 2$ in heterozygous $\mathrm{Nrl}^{+/ b 2}$ mice did not alter retinal morphology or the numbers of rods and cones compared with $+/+$ mice, indicating that coexpression of TR $\beta 2$ with NRL in rod precursors did not divert differentiation from a rod outcome.

\section{Distinct photoreceptor outcomes in $\mathrm{Nrl}^{+/ b 2}, \mathrm{Nrl}^{\mathrm{b2/b2}}$ and $\mathrm{Nrl}^{-1-}$ mice}

The photoreceptor outcomes of the different mouse strains were further determined by analysis of expression of cone and rod photopigments (Fig. 3), by analysis of the spatial distribution of cone photopigments over the retina (Fig. 4A), and by testing the dependence of photopigment expression upon thyroid hormone (Fig. 4B). First, Western blot and mRNA analyses demonstrated that in $N r l^{b 2 / b 2}$ mice, like $\mathrm{Nrl}^{-1-}$ mice, the retina overexpressed $\mathrm{S}$ opsin and lacked the rod photopigment rhodopsin (Fig. 3A,C). However, $\mathrm{Nr}^{b 2 / b 2}$ mice differed from $\mathrm{Nrl}^{-/-}$mice in the key property of overexpression of $\mathrm{M}$ opsin. Heterozygous $\mathrm{Nrl}^{+/ b 2}$ mice showed little or no abnormality in cone opsin or rhodopsin expression, indicating that TR $\beta 2$ is largely constrained from regulating cone opsins in a rod cellular context. The overexpression of $\mathrm{M}$ opsin in $\mathrm{Nr}^{b 2 / b 2}$ mice displayed an early onset and was already pronounced at P14 (Fig. 3B). Similar findings were made at the mRNA level using quantitative PCR analysis (Fig. 3C), indicating that the phenotypic difference between $\mathrm{Nr}^{b 2 / b 2}$ and $\mathrm{Nrl}^{-/-}$mice reflected changes in the transcriptional program. 
A

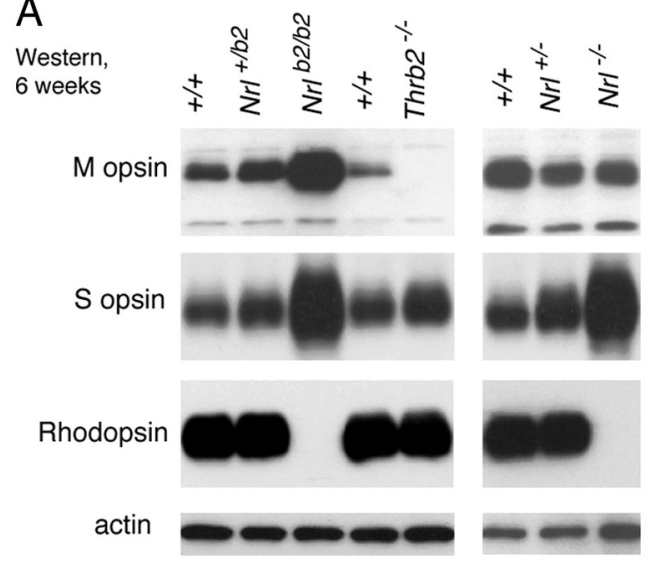

B

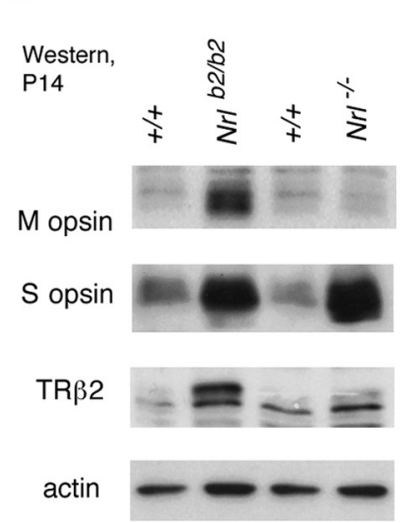

C

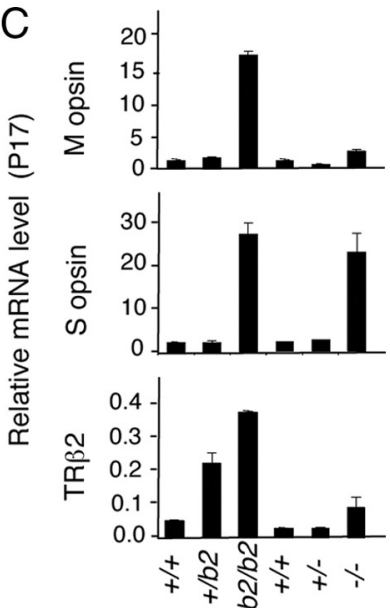

Figure 3. Distinct photoreceptor outcomes in $\mathrm{Nrl}^{\mathrm{b} 2 / \mathrm{b} 2}$ and $\mathrm{Nrl}^{-1-}$ mice. $\boldsymbol{A}$, Western blot analysis of cone opsins and rhodopsin in retina from 6-week-old mice of the indicated $\mathrm{Nrl}$ genotypes. $\mathrm{Thrb2}^{-1-}$ lane, Sample from TR $\beta 2$-deficient mice as a negative control for M opsin. $\boldsymbol{B}$, Western blot analysis of cone opsins and TR $\beta 2$ in retina from P14 mice of the indicated Nrl genotypes. The initial induction of $\mathrm{M}$ opsin is pronounced in $\mathrm{Nr}^{b 2 / b 2}$ mice at this juvenile age. C, Quantitative PCR analysis of M opsin, S opsin, and TR $\beta 2$ mRNA levels in retina of mice of the indicated $N r /$ genotypes at P17.

Normally, $\mathrm{M}$ and S opsins are differentially distributed across the mouse retina, with $\mathrm{M}$ opsin predominating in superior and $\mathrm{S}$ opsin in inferior retinal regions, while cones in middle regions express varying proportions of both $\mathrm{M}$ and $\mathrm{S}$ opsins (Lyubarsky et al., 1999; Applebury et al., 2000; Szél et al., 2000). In the excess S cones in $\mathrm{Nrl}^{-1-}$ mice, this pattern is lost, with $\mathrm{S}$ opsin being strongly overexpressed regardless of regional location in the retina, as shown by in situ hybridization analysis (Fig. 4A). However, ectopic TR $\beta 2$ expression imposed a normal distribution trend on $\mathrm{M}$ and $\mathrm{S}$ opsins in the excess cones in $N r l^{\mathrm{b} 2 / \mathrm{b} 2}$ mice such that $\mathrm{M}$ opsin was predominantly expressed in superior and $\mathrm{S}$ opsin in inferior retinal regions.

Further experiments demonstrated that the excess cones in $\mathrm{Nrl}^{b 2 / 62}$ mice, like normal cones, were dependent on provision of thyroid hormone for $\mathrm{M}$ and $\mathrm{S}$ opsin patterning. $\mathrm{Nr}^{b 2 / b 2}$ mice were made congenitally hypothyroid by crossing with $T s \mathrm{hr}^{-1-}$ mice (Marians et al., 2002; Lu et al., 2009). Tshr ${ }^{-1-}$ mice have very low serum levels of thyroid hormones from birth because of an underdeveloped thyroid gland resulting from loss of the thyrotropin receptor. In $\mathrm{Nrl}^{b 2 / b 2}$ mice on a $\mathrm{Tsh}^{-1-}$ background, M opsin expression was retarded and $\mathrm{S}$ opsin overexpression was exacerbated in both superior and inferior retinal regions (Fig. 4B). Rhodopsin remained undetectable in $N r l^{b 2 / b 2}$ mice regardless of Tshr genotype.

\section{Distinct photoreceptor functions in $\mathrm{Nrl}^{+/ b 2}, \mathrm{Nrl}^{b 2 / \mathrm{b} 2}$, and} $\mathrm{Nrl}^{-1-}$ mice

Analysis of the photopic ERG revealed a striking enhancement of $\mathrm{M}$ cone function in $\mathrm{Nr} l^{b 2 / b 2}$ mice, consistent with the presence of $\mathrm{M}$ opsin in the excess cone photoreceptors in this mouse strain. Cone b-wave magnitudes were substantially elevated in response to a monochromatic light stimulus with a wavelength of $520 \mathrm{~nm}$ that optimally activates mouse M opsin (Lyubarsky et al., 1999; $\mathrm{Ng}$ et al., 2010) (Fig. 5A, top row). In contrast, $\mathrm{Nrl}^{-1-}$ mice displayed $\mathrm{M}$ cone responses in the normal range. Both $\mathrm{Nr}^{b 2 / b 2}$ and $\mathrm{Nrl}^{-1-}$ mice displayed markedly enhanced $\mathrm{S}$ cone responses to a stimulus at $360 \mathrm{~nm}$, a wavelength that optimally activates mouse $\mathrm{S}$ opsin (Fig. 5A, middle row). However, the magnitude of the enhanced $S$ cone response was somewhat lower in $\mathrm{Nrl}^{b 2 / 62}$ mice than in $\mathrm{Nrl}^{-1-}$ mice, as shown in the stimulus intensityresponse plots (Fig. 5B). The smaller enhancement of the $\mathrm{S}$ cone response in $\mathrm{Nr}^{b 2 / b 2}$ mice is consistent with the more restricted distribution of S opsin in the retina in $\mathrm{Nrl}^{b 2 / b 2}$ mice than $\mathrm{Nrl}^{-/-}$ mice. Both $\mathrm{Nrl}^{b 2 / b 2}$ and $\mathrm{Nrl}^{-1-}$ mice lacked scotopic ERG responses as expected in the absence of rods (Fig. 5A, bottom row). In conclusion, these results indicate that in the absence of NRL, both $\mathrm{Nrl}^{b 2 / b 2}$ and $\mathrm{Nrl}^{-/-}$mice produce excess, functional cones instead of rods. However, the results in $\mathrm{Nr}^{b 2 / b 2}$ mice indicate that precursors that would normally become rods are capable of forming functional $\mathrm{M}$ cones, as an alternative to the $\mathrm{S}$ cones found in $\mathrm{Nrl}^{-/-}$mice. Finally, heterozygous $\mathrm{Nrl}^{+/ b 2}$ mice displayed rod responses in the normal range, indicating that in mice with this genotype, the rod population (Fig. 2) was functionally intact.

\section{Transient coexpression of $\mathrm{Nrl}$ and $\mathrm{TR} \beta 2$ in retinal development}

The above evidence from mouse strains carrying genetic alterations demonstrated that precursors that normally form rods are capable of forming $\mathrm{M}$ cones, $\mathrm{S}$ cones, or rods, depending upon the relative expression levels of NRL and TR $\beta 2$. We therefore tested whether common photoreceptor precursors in the normal retina may coexpress the early rod (NRL) and cone (TR $\beta 2)$ markers at immature stages. TR $\beta 2$ was detected by immunofluorescence using antiserum against TR $\beta 2$ (@TR $\beta 2$ ), and $N r l$ expression was monitored by direct detection of green fluorescent protein (GFP) expressed from an $\mathrm{Nrl}$ promoter-GFP transgene (NrlpGFP) on a wild-type mouse background. This direct identification of immature cones and rods based on early markers revealed that the appearance of TR $\beta 2$-positive $(\mathrm{TR} \beta 2+)$ and NrlpGFP-positive $(\mathrm{GFP}+)$ cells followed the profiles of cone and rod genesis, respectively, determined indirectly in previous studies using ${ }^{3} \mathrm{H}$-thymidine labeling in mice (Carter-Dawson and LaVail, 1979b) (Fig. 6A,B). Thus, the cone peak preceded that of rods. However, up to $50 \%$ of $\mathrm{TR} \beta 2+$ cells at later embryonic stages were also GFP + (Fig. 6C). Postnatally, GFP + cell numbers rose sharply, correlating with the peak of rod generation. By P8, no doubly positive cells were detected. The results revealed a transient population of cells that coexpressed TR $\beta 2$ and GFP, raising the possibility that some photoreceptor precursors originate in an indeterminate rather than fixed rod or cone state.

The validity of the NrlpGFP transgene as a marker for cells expressing endogenous $\mathrm{Nrl}$ was verified by analysis with an anti- 
body against NRL protein (@Nrl) (Fig. 6D). Both the antibody and NrlpGFP transgene detected cells with a range of signal strengths in the late embryonic retina. Almost all GFP + cells were also positive for @Nrl. However, the @Nrl antibody detected some additional cells that were not GFP+ (Fig. 6D, white arrows, middle panel), suggesting that NrlpGFP had a slightly lower detection sensitivity than @Nrl antiserum. The presence of cells that were positive for both $\mathrm{Nrl}$ and TR $\beta 2$ was independently demonstrated in a reciprocal analysis using@Nrl to detect endogenous NRL protein and an antibody against $\beta$-galactosidase (@bGal) to detect expression of a targeted lac $Z$ insertion in the TR $\beta 2$-specific exon of the endogenous Thrb gene (Ng et al., 2001). Cells positive for both@bGal and @Nrl were detected in these mice (Fig. 6E).

Using mice carrying NrlpGFP, we investigated whether any GFP+ precursors coexpressed S opsin, an indicator of the putative default $S$ cone state of a precursor before acquisition of a fixed fate. These mice also carried a Thrb2p-lacZ transgene, a reporter of TR $\beta 2$ expression, thus allowing triple analysis of cells expressing $\mathrm{Nrl}, \mathrm{TR} \beta 2$, and S opsin. At late embryonic and neonatal stages, occasional doubly positive GFP+/S opsin + cells were detected (Fig. 6F). Rare triply positive $\mathrm{GFP}+/ \mathrm{TR} \beta 2+/ \mathrm{S}$ opsin + cells were also detected in neonates, suggesting that some precursors may originate in an indeterminate state.

\section{Discussion}

This study of $\mathrm{Nrl}^{b 2 / b 2}$ mice demonstrates that postmitotic precursors that normally form rods possess an innate plasticity and can be directed to three functionally distinct photoreceptor outcomes by NRL and TR $\beta 2$ in vivo. This evidence, based upon manipulation of rod precursors, supports a hypothesis whereby photoreceptor diversity originates in a malleable precursor in response to two, stepwise decisions (Swaroop et al., 2010), as follows. (1) If NRL attains a critical threshold of expression, it suppresses a default $\mathrm{S}$ cone outcome and directs a rod fate. The retention of rods in $\mathrm{Nrl}^{+/ b 2}$ mice suggests that TR $\beta 2$ has little ability to deflect such a cell away from a rod outcome, consistent with NRL exerting transcriptional dominance

(Oh et al., 2007). (2) If NRL expression fails to reach a threshold, differentiation proceeds by default as an $\mathrm{S}$ cone. In a subpopulation of these cells, TR $\beta 2$ determines an M opsin identity depending upon the spatial location of the cone in the retina and the developmental rise in thyroid hormone levels in the circula-
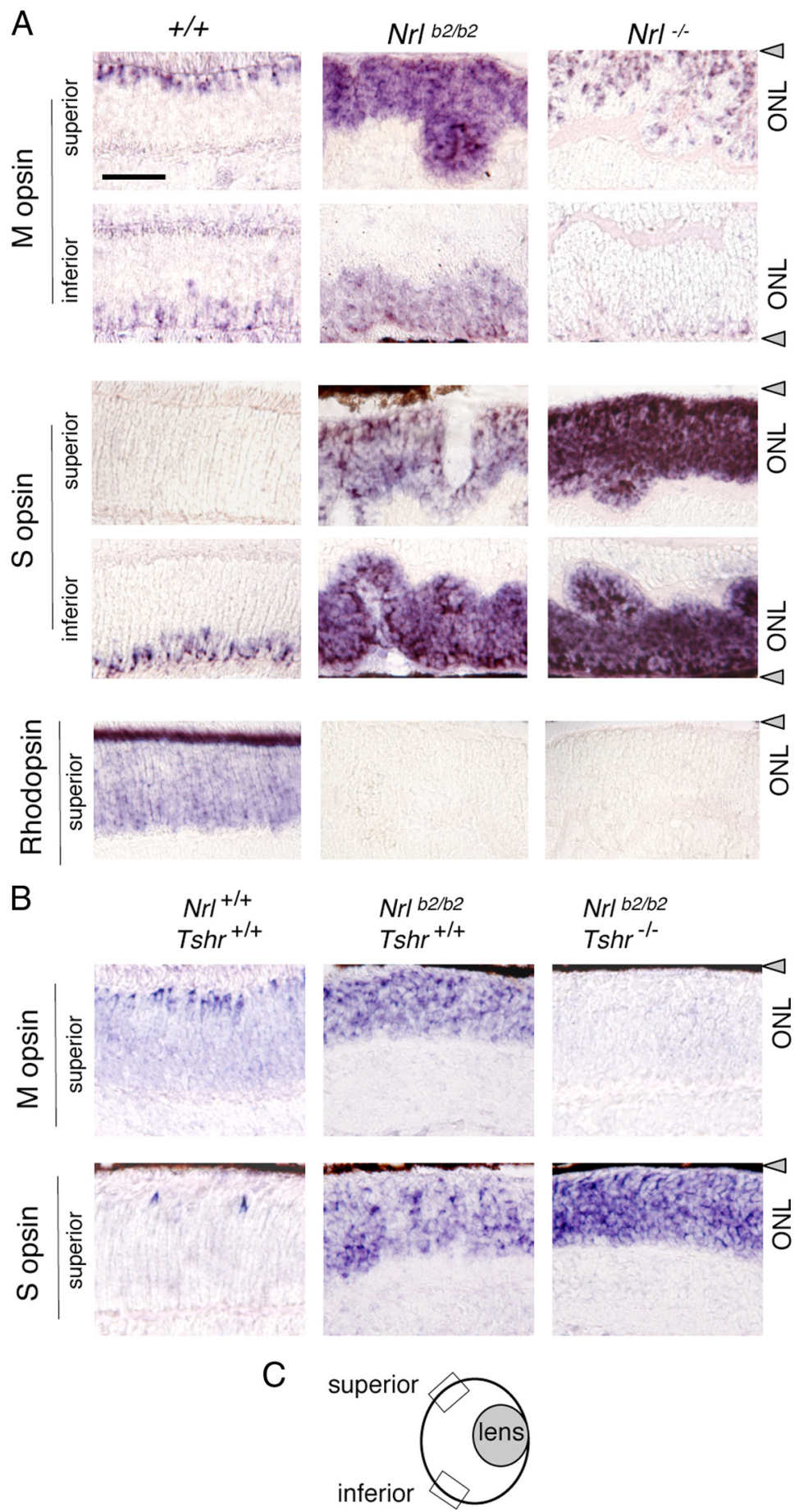

Figure 4. Differential distribution of $\mathrm{M}$ and $\mathrm{S}$ opsins in $\mathrm{Nrl}^{\mathrm{b2} / \mathrm{b2}}$ and $\mathrm{Nrl}^{-1-}$ mice. $\boldsymbol{A}$, In situ hybridization analysis of cone opsin and rhodopsin mRNA in superior and inferior retinal regions in 8-week-old mice. $\mathrm{Nr}^{b 2 / b 2}$ mice overexpressed $\mathrm{M}$ and $\mathrm{S}$ opsins with a normal distribution trend, whereas in $\mathrm{Nrl}^{-1-}$ mice, $\mathrm{S}$ opsin was strongly overexpressed in all retinal regions. $\mathrm{Nrl}^{-1-}$ mice showed a small increase in the density of M opsin-positive cells in superior regions compared with $+/+$ mice, partly due to $0 \mathrm{NL}$ folding in $\mathrm{Nrl}^{-1-}$ mice. $\boldsymbol{B}$, In situ hybridization analysis of opsin mRNA in hypothyroid $\mathrm{Nr}^{b 2 / b 2}$ mice at P17. On a hypothyroid $\mathrm{Tshr}^{-1-}$ background, M opsin expression was retarded and S opsin overexpression exacerbated in $\left.\mathrm{Nr}\right)^{b 2 / b 2}$ mice. Scale bar: $\boldsymbol{A}$ (for $\boldsymbol{A}, \boldsymbol{B}), 50 \mu \mathrm{m}$. $\boldsymbol{C}$, Diagram of mouse eye section indicating location of superior and inferior retinal fields examined (boxes). Gray triangles, Retinal pigmented epithelium. tion (Roberts et al., 2006; Pessôa et al., 2008; Lu et al., 2009; Glaschke et al., 2010). Consequently, the plastic precursor acquires a fixed commitment to a particular photoreceptor fate. A distinctive feature of the hypothesis is the sequential, two-step control, with each step yielding a new outcome (rod or M cone) 
A

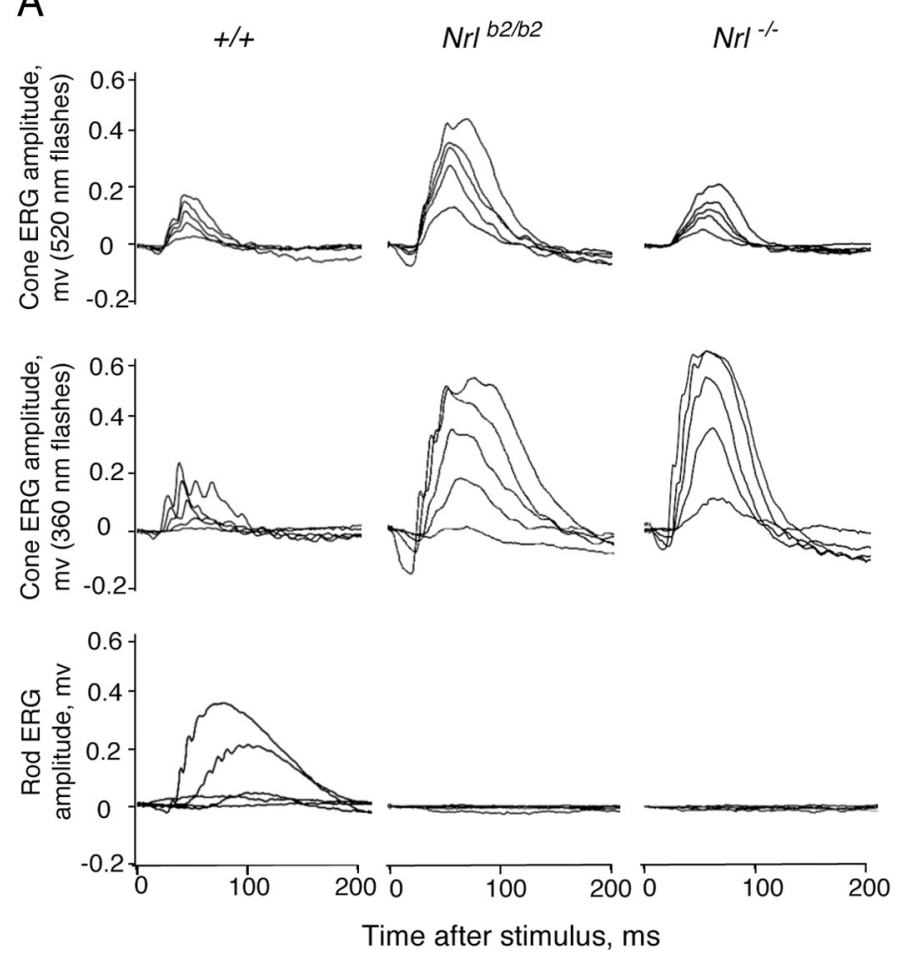

B
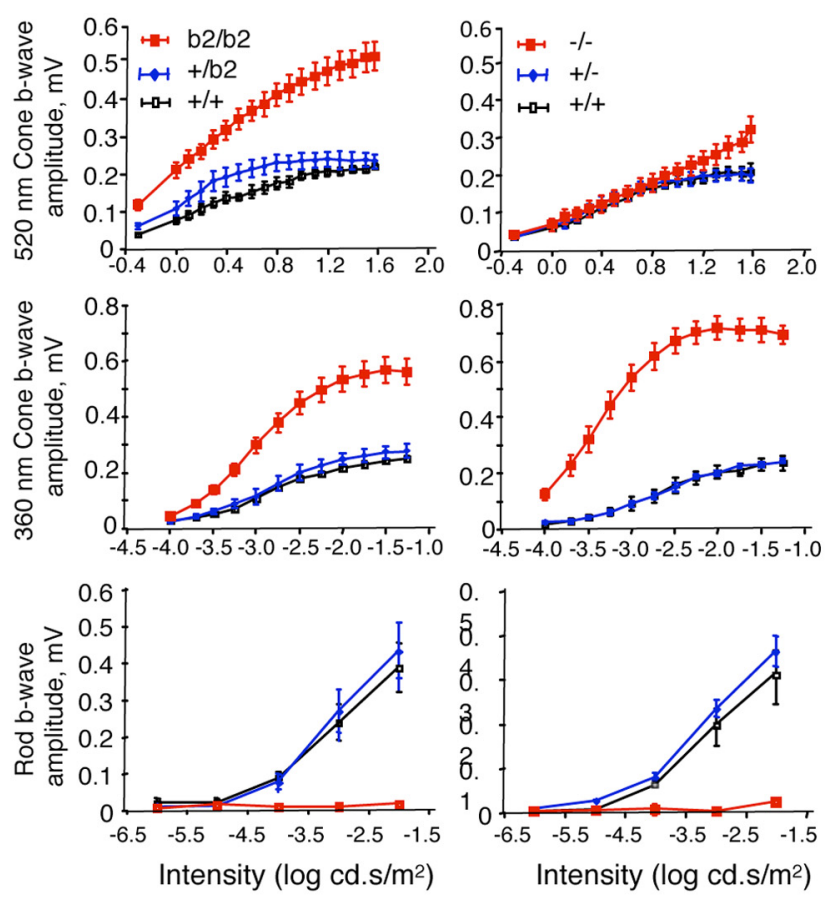

Figure 5. Distinct cone and rod functional responses in $\mathrm{Nrl}^{+/ 62}, \mathrm{Nrl}^{b 2 / b 2}$, and $\mathrm{Nrl}^{-1-}$ mice. $\mathrm{A}$, Representative electroretinogram traces for $\mathrm{Nrl}{ }^{b 2 / b 2}$ and $\mathrm{Nrl}^{-/-}$mice at $\sim 8$ weeks of age. Top and middle rows, Photopic cone responses to stimuli with wavelengths of 520 and $360 \mathrm{~nm}$ that optimally activate mouse M and S opsins, respectively. Bottom row, Scotopic rod responses. Enhanced $M$ and S cone responses were detected in $\mathrm{Nr}^{62 / 62}$ mice, but only enhanced S cone responses in $\mathrm{Nrl}^{-1-}$ mice. Families of traces are shown for light intensities of $0.5,1.26,2,3.16$, and $7.94 \mathrm{~cd} \cdot \mathrm{s} / \mathrm{m}^{2}$ at $520 \mathrm{~nm}$ and $0.0001,0.00032,0.001,0.0032$ and $0.0316 \mathrm{~cd} \cdot \mathrm{s} / \mathrm{m}^{2}$ at $360 \mathrm{~nm}$ for cones and $1 \times 10^{-6}, \times 10^{-5}, \times 10^{-4}, \times 10^{-3}$, and $\times 10^{-2} \mathrm{~cd} \cdot \mathrm{s} / \mathrm{m}^{2}$ for rods. $\boldsymbol{B}$, Intensity-response curves of average ERG responses for groups of $4-6$ mice (means \pm SEM). Cone (top and middle rows) and rod (bottom row) ERG responses to varying stimulus intensities were determined for $+/+$, $\mathrm{Nrl}^{+/ \mathrm{b2}}$, and $\mathrm{Nrl}^{\mathrm{b} / \mathrm{b} 2}$ mice and, separately, for $+/+, \mathrm{Nrl}^{+/-}$, and $\mathrm{Nrl}^{-1-}$ mice. $\mathrm{Nrl}^{\mathrm{b} 2 / \mathrm{b} 2}$ and $\mathrm{Nrl}^{-1-}$ mice were each compared with their own $+/+$ and heterozygous groups on comparable genetic backgrounds.

relative to a common default outcome ( $\mathrm{S}$ cone). This contrasts with other models of cell fate determination in which two transcription factors exert mutual antagonism, as has been proposed, for example, for GATA1 and PU.1 in directing erythroid versus myeloid fates in blood cell differentiation (Graf and Enver, 2009).

Other evidence suggests that precursors of all cone and rod types, not only the rod type, possess innate plasticity. Thus, both TR $\beta 2$-deficient and NRL-deficient mice gain $S$ cones at the expense of $\mathrm{M}$ cones and rods, respectively (Mears et al., 2001; Ng et al., 2001). Moreover, ectopic expression of NRL in all types of photoreceptor precursors using a Crx promoter suppresses cone development and gives a rod-only retina (Oh et al., 2007), indicating that cone precursors are susceptible to the dominant activity of NRL. Based on this evidence and the results from $N r l^{b 2 / b 2}$ mice, we may speculate that photoreceptor precursors possess equivalent plasticity when first generated from dividing progenitors. If so, the first distinction between rod and cone precursors may be set by the presently undefined signals that induce a threshold level of NRL expression in the population that will become rods.

We also detected precursors in normal retina that coexpressed TR $\beta 2$ and $N r l$ using two immunofluorescent approaches. This transient population of doubly positive cells was most evident at late embryonic stages and may reflect the presence of some normal precursors that exist in an indeterminate state before final commitment to a given photoreceptor fate. However, the developmental significance of these doubly positive precursors awaits future investigation, for example by cell lineage-tracing experiments. We note that a technical limitation in monitoring early differentiation stages concerns the changing and, at times very low, expression levels of cone and rod markers in development. For example, TR $\beta 2$ peaks in utero and declines postnatally, whereas $\mathrm{Nrl}$ expression is relatively weak in utero but increases postnatally. Such low and dynamically varying expression levels may lead to an underestimation of the number of doubly positive cells at some stages but would not change the major finding of this analysis.

Much interest has focused on multipotent progenitor cells as a source of neuronal diversity, with differentiation fates being programmed in the progenitor before or during exit from the cell cycle (Jacob et al., 2008; Agathocleous and Harris, 2009; Jukam and Desplan, 2010). Indeed, as development progresses, retinal progenitors are thought to change their differentiation properties, or competence, thereby allowing the generation of appropriate populations of photoreceptors, interneurons, ganglion cells, and glia (Livesey and Cepko, 2001). Nonetheless, concerning the cell type in which photoreceptor diversity arises, our study points to a postmitotic precursor rather than a progenitor as the source of diversity. The process that produces such a generic, plastic photoreceptor precursor from a progenitor is probably complex, involving, for example, Otx2 (Nishida et al., 2003), Blimp1 (Brzezinski et al., 2010; Katoh et al., 2010), and Notch signaling genes (Jadhav et al., 2006; Yaron et al., 2006; Riesenberg et al., 2009). However, NRL and TR $\beta 2$ are not required at this step. Rather, the requirement for $\mathrm{NRL}$ and $\mathrm{TR} \beta 2$ is postponed until a malleable precursor is made that can be directed to a rod, $\mathrm{M}$ cone, or $\mathrm{S}$ cone fate by a limited combination of transcriptional switches. 

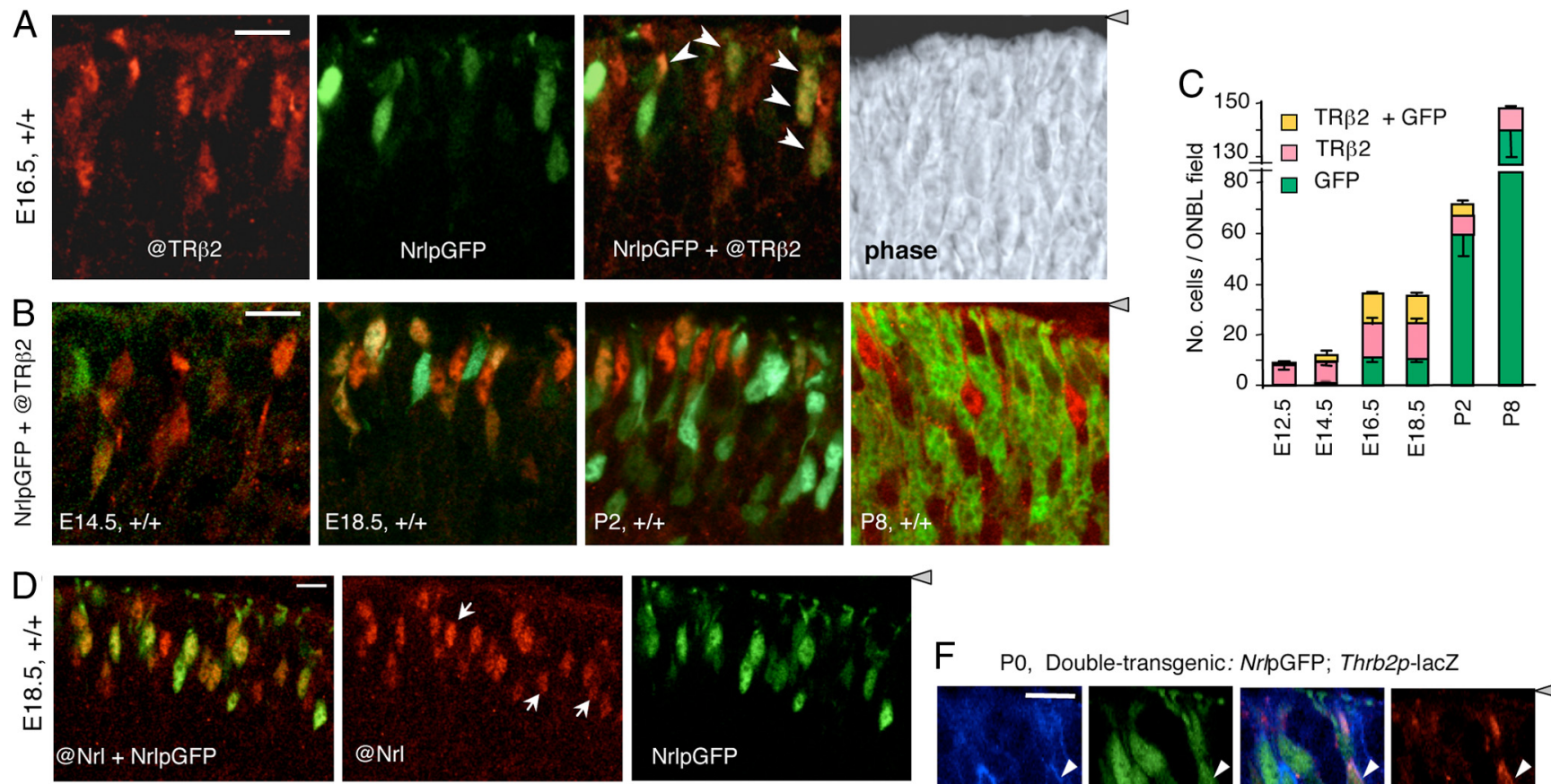

E
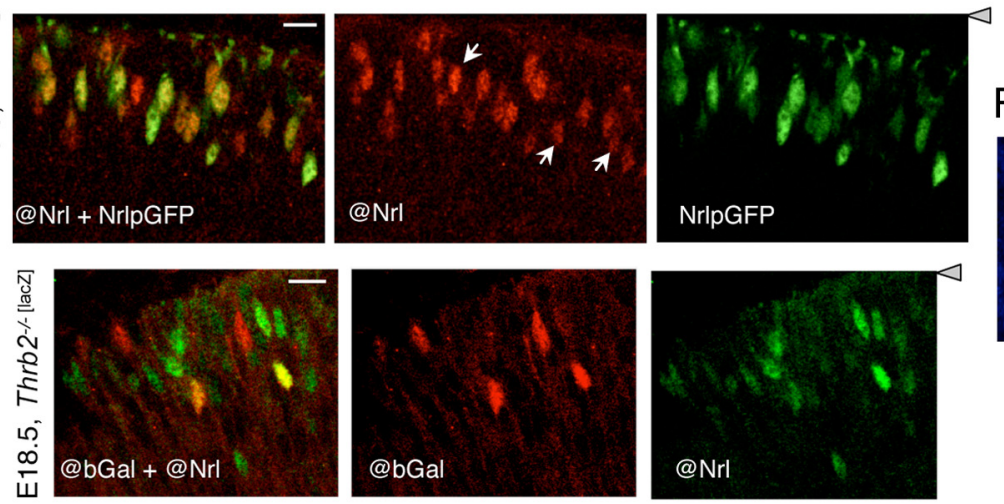

$\mathrm{F}$

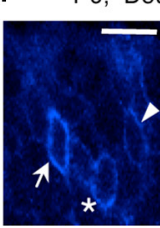

@S opsin

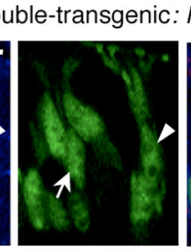

NrlpGFP

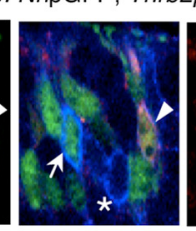

@S opsin @bGal NrlpGFP

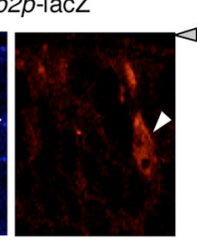

@bGal

Figure 6. Transient coexpression of TR $\beta 2$ and $N r$ in photoreceptor precursors. A, Double fluorescence analysis of cells positive for TR $\beta 2$ (@TR $\beta 2$ antibody, red), Nr/pGFP (transgene, green), or both @TR $\beta 2$ and Nr/pGFP (yellow or orange, arrows in merged image) in the outer neuroblastic layer of $+/+$ mouse retina at E16.5. Right, Phase contrast image of the same field. Confocal microscope images represent a single 1-1.5 $\mu \mathrm{m} z$-plane obtained from $10-\mu \mathrm{m}$-thick mid-retinal cryosections (same in $\boldsymbol{B}-\boldsymbol{E}$ ). For orientation, the gray arrowhead indicates location of retinal pigmented epithelium. $\boldsymbol{B}$, Double fluorescence analysis of cells positive for TR $\beta 2$ and Nr/pGFP in $+/+$ mouse retina during development at E14.5, E18.5, P2, and P8. Doubly positive cells (yellow or orange) were most evident at E16.5-E18.5. Scale bars: $\boldsymbol{A}, \boldsymbol{B}, 14 \mu \mathrm{m}$. $\boldsymbol{C}$, Counts of cells positive for TR $\beta 2$, GFP, or both TR $\beta 2$ and GFP, determined on single $z$-plane confocal images from experiments shown in $\boldsymbol{A}$ and $\boldsymbol{B}$. Counts shown were determined in mid-retinal fields. Counts in superior and inferior fields gave similar results. $\boldsymbol{D}$, Verification of Nr/pGFP transgene as a marker for cells expressing endogenous Nrl using an antibody against NRL protein (@Nrl) and direct fluorescence for Nr/pGFP in + / + embry0s at E18.5. The @Nrl+ population included almost all GFP + cells (yellowish and orange cells, merged image on the left) and a few @Nrl+ cells that were negative for GFP (white arrows, middle).E, Independent identification of cells that coexpress TR 32 (@bGal) and endogenous NRL protein (@Nrl) (yellow or orange cells in merged image, left). Analysis was performed on E18.5 embryos homozygous for a targeted insertion of lacZ in the TR $\beta 2$-specific exon of the Thrb gene. Scale bars: $\boldsymbol{D}, \boldsymbol{E}, 10 \mu \mathrm{m} \boldsymbol{F}$, Immunofluorescence analysis for coexpression of S opsin (@S opsin antibody, blue), Nr/pGFP (direct fluorescence, green) and Thrb2p-lacZ transgenes (@bGal antibody, red, indicator for TR $\beta 2$ ) in +/+ mice at P0. Arrows, S opsin/GFP doubly positive cell; arrowheads, S opsin/GFP/bGal triply positive cell; asterisks, S opsin-positive cell with no detectable GFP or bGal. Gray triangle, Retinal pigmented epithelium.

Genes such as Nr2e3 (Haider et al., 2000), Crx (Chen et al., 1997; Furukawa et al., 1999), and Pias3 (Onishi et al., 2009, 2010) are also critical at various stages of photoreceptor differentiation and encode accessory factors or downstream effectors that participate closely with NRL or TR $\beta 2$. For example, NRL initially induces expression of orphan receptor NR2E3, and these two factors together activate rod genes and suppress cone genes ( $\mathrm{Oh}$ et al., 2007). Coup-TF, retinoid-related orphan nuclear receptors, and retinoid receptors cooperate with $\mathrm{TR} \beta 2$ in setting cone opsin distribution patterns (Roberts et al., 2005; Srinivas et al., 2006; Fujieda et al., 2009; Satoh et al., 2009; Alfano et al., 2011). Although the mechanisms of these interactions remain to be elucidated, current evidence does not indicate that other factors substitute for NRL and TR $\beta 2$ in the central decisions that initiate the generation of photoreceptor diversity.

It is of interest that analogous controls may direct photoreceptor diversity in non-mammalian species. The Drosophila compound eye consists of ommatidial units but nonetheless resembles the mammalian eye in containing both color-sensing and dim light-sensing photoreceptors. In the Drosophila eye, a mosaic of color-sensing photoreceptors is generated by stochastic expression of spineless factor in precursor cells. Spineless dictates which particular opsin is expressed, thereby generating "yellow" or "pale" ommatidial fates (Wernet et al., 2006). Although the factors differ, similarities in the transcriptional switches used in mice and insects may point to common themes underlying the generation of photoreceptor diversity.

\section{References}

Adler R, Raymond PA (2008) Have we achieved a unified model of photoreceptor cell fate specification in vertebrates? Brain Res 1192:134-150.

Agathocleous M, Harris WA (2009) From progenitors to differentiated cells in the vertebrate retina. Annu Rev Cell Dev Biol 25:45-69.

Akimoto M, Cheng H, Zhu D, Brzezinski JA, Khanna R, Filippova E, Oh EC, Jing Y, Linares JL, Brooks M, Zareparsi S, Mears AJ, Hero A, Glaser T, Swaroop A (2006) Targeting of GFP to newborn rods by Nrl promoter and temporal expression profiling of flow-sorted photoreceptors. Proc Natl Acad Sci U S A 103:3890-3895.

Alfano G, Conte I, Caramico T, Avellino R, Arnò B, Pizzo MT, Tanimoto N, Beck SC, Huber G, Dollé P, Seeliger MW, Banfi S (2011) Vax2 regulates retinoic acid distribution and cone opsin expression in the vertebrate eye. Development 138:261-271. 
Applebury ML, Antoch MP, Baxter LC, Chun LL, Falk JD, Farhangfar F, Kage K, Krzystolik MG, Lyass LA, Robbins JT (2000) The murine cone photoreceptor: a single cone type expresses both $\mathrm{S}$ and $\mathrm{M}$ opsins with retinal spatial patterning. Neuron 27:513-523.

Brzezinski J, Reh T (2010) Retinal histogenesis. In: Encyclopedia of the eye, Vol 4 (Dartt D, Besharse J, Dada R, eds), pp 73-80. Amsterdam: Elsevier.

Brzezinski JA 4th, Lamba DA, Reh TA (2010) Blimp1 controls photoreceptor versus bipolar cell fate choice during retinal development. Development 137:619-629.

Carter-Dawson LD, LaVail MM (1979a) Rods and cones in the mouse retina. I. Structural analysis using light and electron microscopy. J Comp Neurol 188:245-262.

Carter-Dawson LD, LaVail MM (1979b) Rods and cones in the mouse retina. II. Autoradiographic analysis of cell generation using tritiated thymidine. J Comp Neurol 188:263-272.

Cepko CL, Austin CP, Yang X, Alexiades M, Ezzeddine D (1996) Cell fate determination in the vertebrate retina. Proc Natl Acad Sci U S A 93:589-595.

Chen S, Wang QL, Nie Z, Sun H, Lennon G, Copeland NG, Gilbert DJ, Jenkins NA, Zack DJ (1997) Crx, a novel Otx-like paired-homeodomain protein, binds to and transactivates photoreceptor cell-specific genes. Neuron 19:1017-1030.

Daniele LL, Lillo C, Lyubarsky AL, Nikonov SS, Philp N, Mears AJ, Swaroop A, Williams DS, Pugh EN Jr (2005) Cone-like morphological, molecular and physiological features of the photoreceptors of the Nrl knockout mouse. Invest Ophthalmol Vis Sci 46:2156-2167.

Fujieda H, Bremner R, Mears AJ, Sasaki H (2009) Retinoic acid receptorrelated orphan receptor $\alpha$ regulates a subset of cone genes during mouse retinal development. J Neurochem 108:91-101.

Furukawa T, Morrow EM, Li T, Davis FC, Cepko CL (1999) Retinopathy and attenuated circadian entrainment in Crx-deficient mice. Nat Genet 23:466-470.

Glaschke A, Glösmann M, Peichl L (2010) Developmental changes of cone opsin expression but not retinal morphology in the hypothyroid Pax8 knockout mouse. Invest Ophthalmol Vis Sci 51:1719-1727.

Graf T, Enver T (2009) Forcing cells to change lineages. Nature 462:587-594.

Haider NB, Jacobson SG, Cideciyan AV, Swiderski R, Streb LM, Searby C, Beck G, Hockey R, Hanna DB, Gorman S, Duhl D, Carmi R, Bennett J, Weleber RG, Fishman GA, Wright AF, Stone EM, Sheffield VC (2000) Mutation of a nuclear receptor gene, NR2E3, causes enhanced S cone syndrome, a disorder of retinal cell fate. Nat Genet 24:127-131.

Jacob J, Maurange C, Gould AP (2008) Temporal control of neuronal diversity: common regulatory principles in insects and vertebrates? Development 135:3481-3489.

Jadhav AP, Mason HA, Cepko CL (2006) Notch 1 inhibits photoreceptor production in the developing mammalian retina. Development 133:913-923.

Jia L, Oh EC, Ng L, Srinivas M, Brooks M, Swaroop A, Forrest D (2009) Retinoid-related orphan nuclear receptor $\operatorname{ROR} \beta$ is an early-acting factor in rod photoreceptor development. Proc Natl Acad Sci U S A 106:17534-17539.

Jones I, Ng L, Liu H, Forrest D (2007) An intron control region differentially regulates expression of thyroid hormone receptor $\beta 2$ in the cochlea, pituitary, and cone photoreceptors. Mol Endocrinol 21:1108-1119.

Jukam D, Desplan C (2010) Binary fate decisions in differentiating neurons. Curr Opin Neurobiol 20:6-13.

Katoh K, Omori Y, Onishi A, Sato S, Kondo M, Furukawa T (2010) Blimp1 suppresses Chx10 expression in differentiating retinal photoreceptor precursors to ensure proper photoreceptor development. J Neurosci 30:6515-6526.

Livesey FJ, Cepko CL (2001) Vertebrate neural cell-fate determination: lessons from the retina. Nat Rev Neurosci 2:109-118.

Lu A, Ng L, Ma M, Kefas B, Davies TF, Hernandez A, Chan CC, Forrest D (2009) Retarded developmental expression and patterning of retinal cone opsins in hypothyroid mice. Endocrinology 150:1536-1544.

Lyubarsky AL, Falsini B, Pennesi ME, Valentini P, Pugh EN Jr (1999) UVand midwave-sensitive cone-driven retinal responses of the mouse: a possible phenotype for coexpression of cone photopigments. J Neurosci 19:442-455.

Marians RC, Ng L, Blair HC, Unger P, Graves PN, Davies TF (2002) Defining thyrotropin-dependent and -independent steps of thyroid hormone synthesis by using thyrotropin receptor-null mice. Proc Natl Acad Sci U S A 99:15776-15781.

Mears AJ, Kondo M, Swain PK, Takada Y, Bush RA, Saunders TL, Sieving PA,
Swaroop A (2001) $\mathrm{Nrl}$ is required for rod photoreceptor development. Nat Genet 29:447-452.

Nathans J (1999) The evolution and physiology of human color vision: insights from molecular genetic studies of visual pigments. Neuron 24:299-312.

Ng L, Hurley JB, Dierks B, Srinivas M, Saltó C, Vennström B, Reh TA, Forrest D (2001) A thyroid hormone receptor that is required for the development of green cone photoreceptors. Nat Genet 27:94-98.

Ng L, Ma M, Curran T, Forrest D (2009) Developmental expression of thyroid hormone receptor $\beta 2$ protein in cone photoreceptors in the mouse. Neuroreport 20:627-631.

Ng L, Lyubarsky A, Nikonov SS, Ma M, Srinivas M, Kefas B, St Germain DL, Hernandez A, Pugh EN Jr, Forrest D (2010) Type 3 deiodinase, a thyroid-hormone-inactivating enzyme, controls survival and maturation of cone photoreceptors. J Neurosci 30:3347-3357.

Nishida A, Furukawa A, Koike C, Tano Y, Aizawa S, Matsuo I, Furukawa T (2003) Otx2 homeobox gene controls retinal photoreceptor cell fate and pineal gland development. Nat Neurosci 6:1255-1263.

Oh EC, Khan N, Novelli E, Khanna H, Strettoi E, Swaroop A (2007) Transformation of cone precursors to functional rod photoreceptors by bZIP transcription factor NRL. Proc Natl Acad Sci U S A 104:1679-1684.

Onishi A, Peng GH, Hsu C, Alexis U, Chen S, Blackshaw S (2009) Pias3Dependent SUMOylation Directs Rod Photoreceptor Development. Neuron 61:234-246.

Onishi A, Peng GH, Chen S, Blackshaw S (2010) Pias3-dependent SUMOylation controls mammalian cone photoreceptor differentiation. Nat Neurosci 13:1059-1065.

Pessôa CN, Santiago LA, Santiago DA, Machado DS, Rocha FA, Ventura DF, Hokoc JN, Pazos-Moura CC, Wondisford FE, Gardino PF, OrtigaCarvalho TM (2008) Thyroid hormone action is required for normal cone opsin expression during mouse retinal development. Invest Ophthalmol Vis Sci 49:2039-2045.

Riesenberg AN, Liu Z, Kopan R, Brown NL (2009) Rbpj cell autonomous regulation of retinal ganglion cell and cone photoreceptor fates in the mouse retina. J Neurosci 29:12865-12877.

Roberts MR, Hendrickson A, McGuire CR, Reh TA (2005) Retinoid X receptor $\gamma$ is necessary to establish the S-opsin gradient in cone photoreceptors of the developing mouse retina. Invest Ophthalmol Vis Sci 46:2897-2904.

Roberts MR, Srinivas M, Forrest D, Morreale de Escobar G, Reh TA (2006) Making the gradient: thyroid hormone regulates cone opsin expression in the developing mouse retina. Proc Natl Acad Sci U S A 103:6218-6223.

Satoh S, Tang K, Iida A, Inoue M, Kodama T, Tsai SY, Tsai MJ, Furuta Y, Watanabe S (2009) The spatial patterning of mouse cone opsin expression is regulated by bone morphogenetic protein signaling through downstream effector COUP-TF nuclear receptors. J Neurosci 29:12401-12411.

Srinivas M, Ng L, Liu H, Jia L, Forrest D (2006) Activation of the blue opsin gene in cone photoreceptor development by retinoid-related orphan receptor $\beta$. Mol Endocrinol 20:1728-1741.

Swain PK, Hicks D, Mears AJ, Apel IJ, Smith JE, John SK, Hendrickson A, Milam AH, Swaroop A (2001) Multiple phosphorylated isoforms of NRL are expressed in rod photoreceptors. J Biol Chem 276:36824-36830.

Swaroop A, Kim D, Forrest D (2010) Transcriptional regulation of photoreceptor development and homeostasis in the mammalian retina. Nat Rev Neurosci 11:563-576.

Szél A, Lukáts A, Fekete T, Szepessy Z, Röhlich P (2000) Photoreceptor distribution in the retinas of subprimate mammals. J Opt Soc Am A Opt Image Sci Vis 17:568-579.

Wernet MF, Mazzoni EO, Celik A, Duncan DM, Duncan I, Desplan C (2006) Stochastic spineless expression creates the retinal mosaic for colour vision. Nature 440:174-180.

Wood WM, Ocran KW, Gordon DF, Ridgway EC (1991) Isolation and characterization of mouse complementary DNAs encoding $\alpha$ and $\beta$ thyroid hormone receptors from thyrotrope cells: the mouse pituitaryspecific $\beta 2$ isoform differs at the amino terminus from the corresponding species from rat pituitary tumor cells. Mol Endocrinol 5:1049-1061.

Yaron O, Farhy C, Marquardt T, Applebury M, Ashery-Padan R (2006) Notch1 functions to suppress cone-photoreceptor fate specification in the developing mouse retina. Development 133:1367-1378.

Young RW (1985) Cell differentiation in the retina of the mouse. Anat Rec 212:199-205. 